\title{
Comparing recruitment strategies in a study of acupuncture for chronic back pain
}

\author{
Karen J Sherman*1, Rene J Hawkes ${ }^{1}$, Laura Ichikawa ${ }^{1}$, Daniel C Cherkin ${ }^{1}$, \\ Richard A Deyo ${ }^{2}$, Andrew L Avins ${ }^{3}$ and Partap S Khalsa ${ }^{4}$
}

\author{
Address: ${ }^{1}$ Group Health Research Institute, 1730 Minor Avenue, Suite 1600, Seattle, WA 98101, USA, ${ }^{2}$ Departments of Family Medicine and \\ Internal Medicine, Oregon Health and Science University, 3181 SW Sam Jackson Park Rd, Portland, OR 97239, USA, ${ }^{3}$ Division of Research, \\ Northern California Kaiser-Permanente, 2000 Broadway, Oakland, CA 94612, USA and ${ }^{4}$ Division of Extramural Research and Training, National \\ Center for Complementary and Alternative Medicine, National Institutes of Health, 6707 Democracy Boulevard, Suite 401, Bethesda, MD 20892, \\ USA \\ Email: Karen J Sherman* - sherman.k@ghc.org; Rene J Hawkes - hawkes.r@ghc.org; Laura Ichikawa - ichikawa.l@ghc.org; \\ Daniel C Cherkin - cherkin.d@ghc.org; Richard A Deyo - deyor@ohsu.edu; Andrew L Avins - Andrew.Avins@ucsf.edu; \\ Partap S Khalsa - khalsap@mail.nih.gov \\ * Corresponding author
}

\section{Published: 27 October 2009}

BMC Medical Research Methodology 2009, 9:69 doi:10.1 186/I47|-2288-9-69

This article is available from: http://www.biomedcentral.com/I47/-2288/9/69

This is an Open Access article distributed under the terms of the Creative Commons Attribution License (http://creativecommons.org/licenses/by/2.0), which permits unrestricted use, distribution, and reproduction in any medium, provided the original work is properly cited.

Received: 7 September 2009

Accepted: 27 October 2009

\begin{abstract}
Background: Meeting recruitment goals is challenging for many clinical trials conducted in primary care populations. Little is known about how the use of different recruitment strategies affects the types of individuals choosing to participate or the conclusions of the study.

Methods: A secondary analysis was performed using data from participants recruited to a clinical trial evaluating acupuncture for chronic back pain among primary care patients in a large integrated health care organization. We used two recruitment methods: mailed letters of invitation and an advertisement in the health plan's magazine. For these two recruitment methods, we compared recruitment success (\% randomized, treatment completers, drop outs and losses to follow-up), participant characteristics, and primary clinical outcomes. A linear regression model was used to test for interaction between treatment group and recruitment method.

Results: Participants recruited via mailed letters closely resembled those responding to the advertisement in terms of demographic characteristics, most aspects of their back pain history and current episode and beliefs and expectations about acupuncture. No interaction between method of recruitment and treatment group was seen, suggesting that study outcomes were not affected by recruitment strategy.

Conclusion: In this trial, the two recruitment strategies yielded similar estimates of treatment effectiveness. However, because this finding may not apply to other recruitment strategies or trial circumstances, trials employing multiple recruitment strategies should evaluate the effect of recruitment strategy on outcome.
\end{abstract}

Trial registration: Clinical Trials.gov NCT00065585. 


\section{Background}

Clinical studies often encounter difficulties in recruiting participants, leading to underpowered studies that fall short of targeted sample sizes [1]. When attempting to augment recruitment to achieve sample size targets, researchers can employ a variety of recruitment strategies [2]. However, different recruitment strategies could conceivably lead to different conclusions about treatment efficacy [3]. This might be particularly true when participants are not masked to treatment and have strong beliefs about the usefulness of the therapy. For example, in studies of complementary and alternative medicine, different populations might have vastly different pre-conceived notions about such treatments and these differences could affect a trial's estimates of treatment effects. Conceivably, persons recruited via advertisements might be more enthusiastic about complementary and alternative medicine and thus, studies using such volunteers might demonstrate greater benefits. Therefore, whenever possible, it is important to determine whether study outcomes are affected by recruitment strategy.

As part of a large trial of acupuncture in two integrated healthcare systems [4], we had the opportunity to use multiple recruitment strategies in one of the study locations. In this report, we compare the effects of two different recruitment strategies in terms of their efficiency, the characteristics of the patients who respond, and their responses to treatment.

\section{Methods}

This study analyzed data collected for a large two-site randomized controlled trial evaluating acupuncture for chronic low back pain. The trial was approved by the institutional review boards for both sites (Group Health in Seattle and Kaiser Permanente in Northern California) where the study was conducted. Participants were individuals with non-specific chronic low back pain of at least three months duration, but who lacked symptoms of sciatica and who had never tried acupuncture for any reason. They were recruited between March 2004 and August 2006 and were randomized to one of three types of acupuncture (individualized, standardized, or simulated acupuncture) or usual care and all four treatments were supplemented with a self-care book. In this trial, participants who received acupuncture or simulated acupuncture had greater improvements in functional status and symptoms at the end of the treatment and at follow-up than those receiving usual medical care. The trial design and primary findings are reported in detail elsewhere $[4,5]$, so only a brief summary is provided here. Participants assigned to acupuncture (or simulated acupuncture) received 10 treatments over 7 weeks (twice weekly for 3 weeks and weekly for 4 weeks). Telephone interviewers masked to treatment conducted follow-up interviews at 8,26 , and 52 weeks. The primary outcomes were backrelated functional status and symptom bothersomeness. At 8 weeks, back symptoms and function had improved in all acupuncture or simulated acupuncture groups. The positive impact of the acupuncture treatments on function was still evident at 52 weeks.

In order to reach our targeted sample size in the Seattle site, we tried a variety of recruitment strategies. Almost $90 \%$ of study participants were recruited through mailed letters and advertisements in the health plan magazine. In

Table I: Study recruitment resolution by recruitment method and randomization group

\begin{tabular}{|c|c|c|c|c|}
\hline \multirow{3}{*}{ No. of responses received } & \multicolumn{2}{|c|}{ Mailed Letter } & \multicolumn{2}{|c|}{ Magazine Advertisement } \\
\hline & \multicolumn{2}{|c|}{859} & \multicolumn{2}{|c|}{410} \\
\hline & $\mathrm{N}$ & $\%$ & $N$ & $\%$ \\
\hline Ineligible & 597 & 69 & 270 & 66 \\
\hline Refused & 36 & 4 & 14 & 3 \\
\hline Unable to contact & 15 & 2 & 4 & 1 \\
\hline Recruitment ended before eligibility asessed & 15 & 2 & 6 & I \\
\hline \multirow[t]{3}{*}{ No. randomized } & 196 & 23 & 116 & 28 \\
\hline & Acupuncture & Usual care & Acupuncture & Usual care \\
\hline & $(N=150)$ & $(N=46)$ & $(\mathrm{N}=85)$ & $(N=3 I)$ \\
\hline No. treatments received & $N(\%)$ & & $N(\%)$ & \\
\hline 0 & $5(3)$ & $\mathrm{N} / \mathrm{A}$ & $4(5)$ & N/A \\
\hline $1-7$ & II (7) & N/A & $6(7)$ & N/A \\
\hline $8-10$ & 134 (89) & N/A & $75(88)$ & N/A \\
\hline \multicolumn{5}{|l|}{ No. of withdrawals } \\
\hline - no follow-up & $3(2)$ & 3 & $3(4)$ & 0 \\
\hline - with follow-up & $9(6)$ & N/A & $6(7)$ & N/A \\
\hline
\end{tabular}


Table 2: Demographic and back pain baseline characteristics of study population by randomization group and recruitment method

\begin{tabular}{|c|c|c|c|c|c|c|c|}
\hline & \multicolumn{2}{|c|}{ Acupuncture } & \multicolumn{2}{|c|}{ Usual care } & \multicolumn{2}{|c|}{ Total } & \multirow[b]{2}{*}{$\begin{array}{r}p \text { for } \\
\text { difference* }\end{array}$} \\
\hline & $\begin{array}{r}\text { Mailed } \\
\text { Letter } \\
(n=150)\end{array}$ & $\begin{array}{r}\text { Magazine } \\
\text { Ad } \\
(n=85)\end{array}$ & $\begin{array}{c}\text { Mailed } \\
\text { Letter } \\
(n=46)\end{array}$ & $\begin{array}{r}\text { Magazine } \\
\text { Ad } \\
(n=3 I)\end{array}$ & $\begin{array}{r}\text { Mailed } \\
\text { Letter } \\
(n=196)\end{array}$ & $\begin{array}{r}\text { Magazine } \\
\text { Ad } \\
(n=116)\end{array}$ & \\
\hline \multicolumn{8}{|l|}{ Demographic characteristics } \\
\hline Age, mean(SD) years & $46(13)$ & $49(13)$ & $45(12)$ & $49(13)$ & $46(13)$ & $49(13)$ & 0.07 \\
\hline Female, $\%$ & 61 & 60 & 61 & 71 & 61 & 63 & 0.70 \\
\hline White, $\%$ & 89 & 93 & 89 & 84 & 89 & 91 & 0.73 \\
\hline Hispanic origin, \% & 4 & 4 & 7 & 0 & 5 & 3 & 0.37 \\
\hline College graduate $\%$ & 52 & 71 & 50 & 58 & 52 & 67 & 0.01 \\
\hline Married, \% & 63 & 55 & 63 & 65 & 63 & 58 & 0.38 \\
\hline Household income $\$ 45,000+/$ year, \% & 66 & 62 & 76 & 74 & 73 & 67 & 0.26 \\
\hline Employed, \% & 81 & 78 & 83 & 71 & 81 & 76 & 0.27 \\
\hline \multicolumn{8}{|l|}{ Back Pain characteristics } \\
\hline Duration of low back pain at least one year, $\%$ & 68 & 58 & 80 & 61 & 71 & 59 & 0.03 \\
\hline Prior surgery, hospitalization or injections, $\%$ & 13 & 8 & 11 & 19 & 12 & 11 & 0.78 \\
\hline $\begin{array}{l}\text { Reduced activity for } 7+\text { days in last } 3 \text { months due to } \\
\text { low back pain, } \%\end{array}$ & 29 & 34 & 30 & 32 & 29 & 34 & 0.42 \\
\hline \multicolumn{8}{|l|}{ Days of pain in last 3 months: } \\
\hline mean (SD) number of days & $68(26)$ & $72(21)$ & $72(25)$ & $78(21)$ & $69(25)$ & $74(21)$ & 0.43 \\
\hline median number of days & 80 & 80 & 90 & 90 & 80 & 83 & \\
\hline Pain below knee $\%$ & 17 & 18 & 17 & 23 & 17 & 19 & 0.63 \\
\hline Symptom bothersomeness, mean (SD) (0-10 scale) & $5.1(2.2)$ & $4.9(2.3)$ & $5.4(2.0)$ & $5.7(2.2)$ & $5.1(2.1)$ & $5.1(2.3)$ & 0.98 \\
\hline RMDQ, mean (SD) (0-23 scale) & $9.9(5.1)$ & $9.5(4.9)$ & $10.6(4.8)$ & $10.0(5.1)$ & $10.1(5.0)$ & $9.6(5.0)$ & 0.45 \\
\hline $\begin{array}{l}\text { Expectation of at least moderate improvement in low } \\
\text { back pain in next year, \% }\end{array}$ & 45 & 44 & 50 & 52 & 46 & 46 & 0.99 \\
\hline
\end{tabular}

$* \mathrm{p}<0.05$ is indicated in bold typeface

Abbreviation: RMDQ, Roland Morris Disability Questionnaire

previous studies, we had largely recruited using mailed letters and thus, were interested in knowing whether the individuals recruited through advertisements were similar to those recruited by mailed letters in terms of their sociodemographic and back pain characteristics, their beliefs about acupuncture, and their treatment outcomes. The remaining $10 \%$ of Seattle study participants were recruited by clinic fliers, the study website, or by referral from someone who became aware of the study. Those individuals were excluded from this analysis because there were so few of them. We also excluded individuals recruited at the Oakland site from this analysis because all but 30 of the 287 Oakland participants were recruited by means of mailed letters to persons having recently receiving care for back pain.

\section{Recruitment Strategies}

Recruitment by mail

Using automated visit data, members of Group Health in Seattle whose visits to healthcare providers resulted in diagnoses consistent with non-specific low back pain were identified. Three to 12 months after their visit, potential participants were mailed a letter that explained the study, described eligibility requirements, and invited participation. If interested in participating, members returned a signed statement indicating their willingness to be contacted by study staff. An interviewer phoned those members to answer questions and determine eligibility using a computer-assisted screening program. Eligible members were guided through the consent process by an interviewer who then sent a copy of the consent form for them to sign and return. Once written consent was obtained, another interviewer contacted the potential participant to administer the baseline questionnaire. If still willing to participate, participants were randomized to one of four groups (two types of acupuncture, simulated acupuncture or usual care). If the participant was randomized to acupuncture or simulated acupuncture, the interviewer scheduled the first two acupuncture appointments.

Recruitment by advertisement in health plan magazine Advertisements were placed in the health plan's quarterly magazine on five occasions at three to six month intervals between October 2004 and April 2006. The advertisement instructed interested persons to call the toll-free number and leave their name and phone number. All prospective 
participants were telephoned by an interviewer, any questions were answered and if appropriate, their eligibility was determined with the assistance of a computer-screening program. If eligible, the member was guided through the consent and baseline interview process using the same procedures described above.

\section{Outcome Measures}

Treatment completion and loss to follow-up

The number of completed treatments (characterized in this report as none, 1 to 7 , or 8 to 10 for the acupuncture and simulated acupuncture groups), with 8 to 10 treatments representing a full course of treatment, was obtained. In addition, formal treatment drop-outs and those withdrawing from follow-up were also assessed.

\section{Baseline characteristics}

Demographic variables, back pain history and characteristics of current episode, satisfaction with back pain care, current use of medication and exercise for back pain, and knowledge and expectations of acupuncture as well as preferred treatment for back pain were collected at baseline.

\section{Follow-up outcomes}

At 8, 26, and 52 weeks, telephone interviews were conducted by persons unaware of the participant's treatment assignment. For this manuscript, we present data for the primary treatment outcomes, back-related functional status and symptom bothersomeness by recruitment source. The Roland Morris Disability Questionnaire (RMDQ), which is reliable, valid and appropriate for telephone

Table 3: Additional baseline characteristics of study population by randomization group and recruitment method

\begin{tabular}{|c|c|c|c|c|c|c|c|}
\hline & \multicolumn{2}{|c|}{ Acupuncture } & \multicolumn{2}{|c|}{ Usual care } & \multicolumn{2}{|c|}{ Total } & \multirow[b]{2}{*}{$\begin{array}{r}p \text { for } \\
\text { difference* }\end{array}$} \\
\hline & $\begin{array}{r}\text { Mailed } \\
\text { Letter } \\
(n=150)\end{array}$ & $\begin{array}{r}\text { Magazine } \\
\text { Ad } \\
(n=85)\end{array}$ & $\begin{array}{c}\text { Mailed } \\
\text { Letter } \\
(n=46)\end{array}$ & $\begin{array}{r}\text { Magazine } \\
\text { Ad } \\
(n=31)\end{array}$ & $\begin{array}{r}\text { Mailed } \\
\text { Letter } \\
(n=196)\end{array}$ & $\begin{array}{r}\text { Magazine } \\
\text { Ad } \\
(n=|| 6)\end{array}$ & \\
\hline \multicolumn{8}{|c|}{ Back pain: satisfaction with prior care and some concurrent treatments } \\
\hline Medication use in past week, $\%$ & 67 & 64 & 72 & 65 & 68 & 64 & 0.43 \\
\hline Satisfaction with care: overall, \% & & & & & & & 0.002 \\
\hline Very or somewhat satisfied & 45 & 32 & 39 & 39 & 43 & 34 & \\
\hline Not satisfied or dissatisfied & 51 & 53 & 59 & 52 & 53 & 53 & \\
\hline Missing & 4 & 15 & 2 & 10 & 4 & 14 & \\
\hline $\begin{array}{l}\text { At least moderately agree will try to manage back pain } \\
\text { by self in future, } \%\end{array}$ & 23 & 20 & 17 & 23 & 22 & 21 & 0.80 \\
\hline \multicolumn{8}{|l|}{ Back exercise in past week: } \\
\hline$\%$ any & 66 & 69 & 59 & 7I & 64 & 70 & 0.32 \\
\hline mean (SD) number of days & $2.5(2.4)$ & $2.5(2.4)$ & $2.3(2.4)$ & $3.0(2.6)$ & $2.5(2.4)$ & $2.6(2.4)$ & 0.47 \\
\hline median number of days & 2.0 & 2.0 & 2.0 & 3.0 & 2.0 & 2.0 & \\
\hline \multicolumn{8}{|l|}{ Active exercise in past week: } \\
\hline$\%$ any & 73 & 84 & 80 & 74 & 74 & 81 & 0.18 \\
\hline mean (SD) number of days & $2.6(2.2)$ & $3.3(2.2)$ & $2.8(1.9)$ & $2.8(2.3)$ & $2.6(2.1)$ & $3.2(2.2)$ & 0.03 \\
\hline median number of days & 2.0 & 3.0 & 3.0 & 2.0 & 3.0 & 3.0 & \\
\hline \multicolumn{8}{|l|}{ Treatment expectations, preferences, and knowledge } \\
\hline $\begin{array}{l}\text { Expectation of helpfulness of acupuncture, mean (SD) } \\
(0-10 \text { scale) (based on non-missing data) }\end{array}$ & $6.3(1.8)$ & $6.6(1.8)$ & $7.0(1.7)$ & $6.9(1.8)$ & $6.5(1.8)$ & $6.6(1.8)$ & 0.44 \\
\hline Preferred treatment, $\%$ & & & & & & & 0.29 \\
\hline Acupuncture & 25 & 37 & 33 & 36 & 28 & 38 & \\
\hline Other CAM & 43 & 38 & 33 & 32 & 42 & 38 & \\
\hline Conventional & 25 & 20 & 33 & 26 & 28 & 23 & \\
\hline Other/Unknown & 7 & 6 & 2 & 7 & I & 2 & \\
\hline Any knowledge of acupuncture, \% & 32 & 38 & 33 & 48 & 32 & 41 & 0.13 \\
\hline Told about acupuncture effectiveness, \% & & & & & & & 0.33 \\
\hline Very effective & 27 & 34 & 30 & 23 & 28 & 31 & \\
\hline Less than very effective & 32 & 31 & 22 & 42 & 30 & 34 & \\
\hline Unknown & $4 I$ & 35 & 48 & 36 & 42 & 35 & \\
\hline Impression of acupuncture, \% & & & & & & & 0.17 \\
\hline Very positive & 21 & 25 & 22 & 23 & 21 & 24 & \\
\hline Moderately positive & 28 & 42 & 44 & 32 & 32 & 40 & \\
\hline Negative or Slightly positive & 51 & 33 & 35 & 45 & 47 & 36 & \\
\hline
\end{tabular}

$*_{\mathrm{p}}<0.05$ is indicated in bold typeface 
administration, was used to measure back-related functional status [6]. Symptom bothersomenenss, which is highly correlated with pain intensity in our data $(r=0.80$, $\mathrm{p}<0.0001$ ), was measured by asking participants to rate how bothersome their pain had been during the past week on a 0 ("not at all bothersome") to 10 ("extremely bothersome") scale.

\section{Statistical Analyses}

Participant flow was reported as frequencies and percentages. Baseline characteristics were displayed as means (and standard deviations) or percentages. Because we did not find differences in outcomes between the acupuncture and simulated acupuncture groups, results are presented comparing any acupuncture or simulated acupuncture treatment with usual care. For simplicity, the acupuncture and simulated acupuncture groups are subsequently referred to as the "acupuncture group". When testing for differences between sources of recruitment, we used t-tests for continuous variables (means), Wilcoxon non-parametric tests for differences in ranks (medians), and chi square tests or Fisher exact tests for categorical variables. A linear regression model was used to examine whether or not the association between treatment group and primary outcomes differed by recruitment method. The model included main effects for treatment group and recruitment method and an interaction between these two to test for effect modification. The model was repeated at each follow-up time point and for each primary outcome: RMDQ and symptom bothersomeness. Including educational status and back pain duration in these models did not change the outcomes, so results are based on models without additional covariates. We used SAS/STAT Version 9.1 [7] and all tests of significance were two-sided.

\section{Results \\ Response Rates by Recruitment Strategy}

We received responses from 1269 individuals, of whom 859 responded to invitation letters and 410 responded to a magazine advertisement (Table 1 ). Only 13 persons who responded to the magazine advertisement had previously been mailed an invitation letter.

Slightly more of those responding to the magazine advertisements were ultimately enrolled in the study $(28.2 \%$ of magazine responders versus $22.8 \%$ of letter invitees; $\mathrm{p}=$ 0.03 ). However, the proportion of persons randomized to acupuncture who completed at least 8 of the 10 treatments was virtually identical for both recruitment methods ( $88 \%$ vs. $89 \%$; $p=0.96)$. Eight percent ( 12 of 150 ) of the persons in the acupuncture group recruited by mail withdrew from treatment early vs. $10.6 \%$ ( 9 of 85 ) of those responding to the magazine advertisements $(\mathrm{p}=$ 0.49 ). Most of the persons withdrawing from treatment agreed to telephone follow-up interviews $(75 \%$ of letter invitees who withdrew vs. $67 \%$ of magazine advertise-

Table 4: Unadjusted mean difference from baseline to follow-up for outcomes by treatment group and recruitment method

\begin{tabular}{|c|c|c|c|c|c|c|c|c|c|}
\hline \multirow{2}{*}{$\begin{array}{l}\text { Follow-up } \\
\text { Interval } \\
\text { Outcome }\end{array}$} & \multicolumn{4}{|c|}{ Acupuncture } & \multicolumn{4}{|c|}{ Usual care } & \multirow{2}{*}{$\begin{array}{c}\text { Test for } \\
\text { interaction of } \\
\text { treatment group } \\
\text { and recruitment } \\
\text { method }\end{array}$} \\
\hline & & Mailed Letter & & $\begin{array}{l}\text { lagazine } \\
\text { ertisement }\end{array}$ & & Mailed Letter & & $\begin{array}{l}\text { lagazine } \\
\text { ertisement }\end{array}$ & \\
\hline & $\mathrm{N}$ & $\begin{array}{c}\text { Mean } \\
(95 \% \mathrm{Cl})\end{array}$ & $N$ & $\begin{array}{c}\text { Mean } \\
(95 \% \mathrm{Cl})\end{array}$ & $N$ & $\begin{array}{c}\text { Mean } \\
(95 \% \mathrm{Cl})\end{array}$ & $N$ & $\begin{array}{c}\text { Mean } \\
(95 \% \mathrm{Cl})\end{array}$ & \\
\hline \multicolumn{10}{|l|}{ 8-week } \\
\hline $\begin{array}{l}\text { Symptom } \\
\text { bothersomeness }\end{array}$ & 144 & $-1.8(-2.3,-1.4)$ & 81 & $-1.6(-2.2,-1.0)$ & 41 & $-0.8(-1.5,-0.1)$ & 30 & $-1.5(-2.5,-.05)$ & 0.82 \\
\hline RMDQ & 144 & $-3.8(-4.7,-2.9)$ & 82 & $-3.3(-4.4,-2.1)$ & 41 & $-0.9(-2.3,+0.5)$ & 30 & $-2.3(-3.7,-1.0)$ & 0.99 \\
\hline \multicolumn{10}{|l|}{ 26-week } \\
\hline $\begin{array}{l}\text { Symptom } \\
\text { bothersomeness }\end{array}$ & 143 & $-1.3(-1.8,-0.8)$ & 82 & $-1.6(-2.3,-1.0)$ & 40 & $-1.4(-2.2,-0.5)$ & 29 & $-1.4(-2.5,-0.3)$ & 0.30 \\
\hline RMDQ & 143 & $-3.5(-4.4,-2.5)$ & 82 & $-3.8(-4.8,-2.8)$ & 40 & $-2.5(-4.1,-1.0)$ & 29 & $-2.5(-4.2,-0.7)$ & 0.25 \\
\hline \multicolumn{10}{|l|}{ 52-week } \\
\hline $\begin{array}{l}\text { Symptom } \\
\text { bothersomeness }\end{array}$ & 140 & $-1.4(-1.9,-0.9)$ & 80 & $-1.8(-2.4,-1.1)$ & 38 & $-1.5(-2.4,-0.6)$ & 30 & $-1.3(-2.2,-0.3)$ & 0.20 \\
\hline RMDQ & 140 & $-3.5(-4.4,-2.7)$ & 80 & $-4.1(-5.1,-3.1)$ & 38 & $-3.2(-4.7,-1.8)$ & 30 & $-2.4(-4.4,-0.4)$ & 0.17 \\
\hline
\end{tabular}

Note: main effect of recruitment method is not significant in any of the models Abbreviation: RMDQ, Roland Morris Disability Questionnaire 
ment enrollees who withdrew; $\mathrm{p}=1.0$ ). Three of the 46 persons in the usual care group recruited by invitation letters withdrew from the study versus none of 31 in the magazine advertisement group $(\mathrm{p}=0.27)$.

\section{Baseline Characteristics by Recruitment Strategy}

Tables 2 and 3 present the baseline characteristics of persons by randomized treatment group and recruitment strategy. Among demographic characteristics, only educational status differed for the two methods of recruitment. Those responding to the health plan magazine advertisements were more likely to be college graduates $(p=0.01)$.

Overall, history of back pain and the intensity of the current episode, including both primary outcome measures, were reassuringly similar for the two recruitment strategies. However, a somewhat higher proportion of persons recruited via mailed letters reported that their back pain had lasted at least a year $(\mathrm{p}=0.03)$. In addition, persons recruited via mailed letters were more likely to report being "very or somewhat satisfied" with the overall care they had received for back pain in the past (Table 3, p, = 0.002 , respectively). Finally, persons recruited via mailed letters exercised slightly fewer days per week (Table 3, p = $0.03)$.

Expectation of acupuncture's helpfulness, preferred treatment for back pain, knowledge of acupuncture, previous information about acupuncture's effectiveness, and impression of acupuncture did not differ substantially by recruitment method.

\section{Primary Outcomes by Recruitment Strategy}

Table 4 displays change scores for symptom bothersomeness and functional disability (RMDQ) in the acupuncture and usual care groups by recruitment method at the three follow-up periods. At all three time points and for both primary outcomes, the interaction between treatment group and recruitment method was not statistically significant. This demonstrates that outcomes by treatment group were similar for both recruitment strategies.

\section{Discussion}

Our estimates of the benefit of acupuncture for chronic low back pain were not affected by recruitment strategy. Sociodemographic characteristics, back pain history and past treatments, and perceptions and expectations about their back pain and about acupuncture were also unaffected by recruitment strategy.

A previous study of transcutaneous electrical nerve stimulation for chronic back pain compared the characteristics of persons recruited via media advertisements with regular patients from a pain clinic [8]. This study found substantial differences between the populations recruited using these different methods in back pain history and characteristics, employment status, and improvement over a 4 to 6 week period. They recommended that researchers pay careful attention to the method of recruitment so that the readers can understand how to apply the results of their findings.

Our study participants had never had acupuncture before and likely resembled primary care patients who fail to obtain adequate relief for their back pain from conventional treatments. In fact, cohort studies in other primary care populations have found similar levels of dysfunction among primary care consulters for low back pain $[9,10]$. These data suggest that our methods of recruitment resulted in a study population whose outcomes may be broadly applicable to a variety of primary care populations.

Strengths of this study included a comprehensive battery of baseline questions and a similar procedure for enrollment in the study regardless of recruitment strategy. However, because we could not distinguish between acute and chronic back pain using diagnoses included in electronic medical records, we cannot estimate how representative the responders to mailed invitations were to the group of persons who sought care for chronic back pain, for example by comparison to medical records of persons with chronic back pain. In addition, because our patients were recruited from an integrated health care system, we do not know how representative they would be of all primary care patients seeking care for chronic back pain.

Although our finding that recruitment method did not influence study outcomes in this acupuncture trial was reassuring, we cannot be certain that this would be true for other types of complementary medicine. We recommend that other studies using multiple strategies for recruitment evaluate whether these impact the study outcomes.

\section{Conclusion}

The characteristics of persons with chronic low back pain recruited for a trial of acupuncture using two different strategies were remarkably similar. Of most importance, the estimated benefits of acupuncture were similar for the two recruitment strategies. However, this may not always be the case and future trials should evaluate the importance of recruitment strategy on outcome.

\section{Competing interests}

The authors declare that they have no competing interests.

\section{Authors' contributions}

KJS and RJH led the author team in the conceptualization and design of the analysis involved in this report; $\mathrm{RJH}$ and 
LI conducted the analysis; all authors were involved in interpretation of the findings; KJS, DCC, LI and RJH drafted the manuscript and all authors read and approved the final manuscript.

\section{Acknowledgements}

The National Center for Complementary and Alternative Medicine (NCCAM) funded this study through a Cooperative Agreement (UOI AT 00I I I0). Dr. Partap Khalsa, Project Officer for NCCAM, was involved in the analysis and interpretation of data and review and approval of the manuscript. The contents of this publication are solely the responsibility of the authors and do not necessarily represent the official views of NCCAM.

We also thank Lhasa OMS, Weymouth Massachusetts, for donating the Seirin acupuncture needles used in this study. We also thank the original members of the SPINE study team for their contributions to the conduct of the trial.

\section{References}

I. Foy R, Parry J, Duggan A, Delaney B, Wilson S, Lewin-Van Den Broek NT, Lassen A, Vickers L, Myres P: How evidence based are recruitment strategies to randomized controlled trials in primary care? Experience from seven studies. Fam Pract 2003, 20(I):83-92.

2. Watson JM, Torgerson $\mathrm{D}$ ): Increasing recruitment to randomised trials: a review of randomised controlled trials. $B M C$ Med Res Methodol 2006, 6:34.

3. Geraets IJ, de Groot IJ, Goossens ME, de Bruijn CP, de Bie RA, Heuvel WJ van den, Dinant GJ: Comparison of two recruitment strategies for patients with chronic shoulder complaints. $\mathrm{Br} / \mathrm{Gen}$ Pract 2006, 56(523): I 27-I33.

4. Cherkin DC, Sherman KJ, Avins AL, Erro JH, Ichikawa L, Barlow WE, Delaney K, Hawkes R, Hamilton L, Pressman A, et al: A randomized trial comparing acupuncture, simulated acupuncture, and usual care for chronic low back pain. Arch Intern Med 2009, 169(9):858-866.

5. Cherkin DC, Sherman KJ, Hogeboom CJ, Erro JH, Barlow WE, Deyo RA, Avins AL: Efficacy of acupuncture for chronic low back pain: protocol for a randomized controlled trial. Trials 2008, 9:10.

6. Patrick DL, Deyo RA, Atlas SJ, Singer DE, Chapin A, Keller RB: Assessing health-related quality of life in patients with sciatica. Spine 1995, 20(17): 1899-1908.

7. SAS Institute I: SAS/STAT ${ }^{\circledR}$ 9.I User's Guide. Cary, NC: SAS Institute, Inc; 2004.

8. Deyo RA, Bass JE, Walsh NE, Schoenfeld LS, Ramamurthy S: Prognostic variability among chronic pain patients: implications for study design, interpretation, and reporting. Arch Phys Med Rehabil 1988, 69(3 Pt I): I74-178.

9. Carey TS, Garrett J, Jackman A, McLaughlin C, Fryer J, Smucker DR: The outcomes and costs of care for acute low back pain among patients seen by primary care practitioners, chiropractors, and orthopedic surgeons. The North Carolina Back Pain Project. N Engl J Med 1995, 333(14):9/3-917.

10. Dunn KM, Croft PR: Repeat assessment improves the prediction of prognosis in patients with low back pain in primary care. Pain 2006, I 26(I-3): I0-15.

\section{Pre-publication history}

The pre-publication history for this paper can be accessed here:

http://www.biomedcentral.com/1471-2288/9/69/prepub
Publish with Biomed Central and every scientist can read your work free of charge

"BioMed Central will be the most significant development for disseminating the results of biomedical research in our lifetime. "

Sir Paul Nurse, Cancer Research UK

Your research papers will be:

- available free of charge to the entire biomedical community

- peer reviewed and published immediately upon acceptance

- cited in PubMed and archived on PubMed Central

- yours - you keep the copyright

Submit your manuscript here:

http://www.biomedcentral.com/info/publishing_adv.asp
BioMedcentral 